\title{
Econophysics: Making Sense of a Chimera*
}

\author{
Adrian K. Yee \\ Forthcoming in European Journal for the Philosophy of Science
}

\begin{abstract}
The history of economic thought witnessed several prominent economists who took seriously models and concepts in physics for the elucidation and prediction of economic phenomena. Econophysics is an emerging discipline at the intersection of heterodox economics and the physics of complex systems, with practitioners typically engaged in two overlapping but distinct methodological programs. The first is to export mathematical methods used in physics for the purposes of studying economic phenomena. The second is to export mechanisms in physics into economics. A conclusion is drawn that physics transfer is often justified at the level of mathematical transfer but unjustified at the level of mechanistic transfer.
\end{abstract}

\section{Introduction}

Interdisciplinary transfer of methods and models has been a hallmark of the history of science, especially in the interactions between the history of economic thought and the history of physics. The idea that the supply and demand in a market may reach an 'equilibrium' arises at least as early as the 18th-century, and was closely tied to developments in theories of elementary mechanics, especially in the work of engineer Achille-Nicholas Isnard (Ingrao \& Israel, 1990). This historical period marks the beginnings of a wave of 'physics transfer', which involves the usage, reference, drawing of analogy, or literal borrowing of concepts from physics to economics. In The Wealth of Nations, Adam Smith posits the following 'gravity model of price' (Smith [1776] 2012, 62):

${ }^{*}$ Correspondence may be addressed to Adrian K. Yee, University of Toronto, Institute for the History \& Philosophy of Science \& Technology (IHPST); e-mail: adriankyle.yee@mail.utoronto.ca. Thanks to the following for constructive feedback: Chris Atkinson, Joseph Berkovitz, Tim Cejka, John B. Davis, Jesse Hall, Julia Lücke, Soroush Marouzi, Michael E. Miller, Mark S. Peacock, Kate Tong, Tracy Wan, two anonymous referees, and audience members attending my talks at the 46th Annual History of Economics Society Meeting at Columbia University (Aug 2019), the 1st Winter Institute for the History of Economic Thought at Arizona State University (Jan 2020), and the 1st Philosophy of Physics Graduate Conference at the University of Oxford (Feb 2020). I thank the IHPST for funding and the University of Cambridge History \& Philosophy of Science Department for an academic home where this paper was written.

${ }^{1}$ I borrow this term from Boumans (1993) who described the attempts of physicist Paul Ehrenfest and the economist Jan Tinbergen to apply the formalism of Hamiltonians and the adiabatic method to business cycles analysis. 
"The natural price...is...the central price, to which the prices of all commodities are continually gravitating...[W]hatever may be the obstacles which hinder them from settling in this centre of repose and continuance, they are constantly tending towards it."

However, Smith's inspiration from Newtonian gravity functioned only as a heuristic for price theory; it took until the 1870's for physical analogies to be taken more seriously as a guide to economic theorizing. This was particularly evident in the works of William Stanley Jevons, Irving Fisher, and Francis Ysidro Edgeworth. What was novel about these figures was the conviction that economic phenomena were sufficiently similar to physical systems such that transferring models from physics to economics was not only often warranted but highly fruitful for both explanatory and predictive purposes. Such transfer was manifested to differing degrees in two general ways: a transference of mathematical methods and of mechanisms.

More recently, the discipline of 'econophysics' exemplifies an even stronger form of physics transfer, advocating ever more sophisticated methods and models from physics for the study of economics and finance. Physics transfer has only recently received attention from philosophers of science (Rickles 2007; Thébault et al. 2018), with relatively few systematic accounts of the ontology and model transfer espoused by its advocates (Rickles 2011). An analysis of physics transfer in econophysics helps to shed light on several contemporary issues in the philosophy of science, including the ways in which models migrate from one field to another (Bradley \& Th'ebault 2019) and the extent at which there can be a realist account of 'structural mechanisms' in econophysics (Kuhlmann 2014; Kuhlmann 2019). However, an articulation of the idiosyncratic and often unclear ways in which econophysicists have transferred mathematical methods and mechanisms from physics to economics has yet to be forthcoming.

This paper provides a systematic analysis, by way of an integrated history and philosophy of science approach, of issues with the usage of several mainstream methods and models in econophysics. Two central theses are defended. Firstly, I argue that the exportation of the mathematical formalisms of physics for the purposes of studying economic phenomena is justified only insofar as such formalisms are articulated within models that are empirically adequate. Since many econophysical theories satisfy this requirement, econophysical usages of mathematics are often justified. Secondly, I will argue against the many attempts to import the mechanisms of physics into economics given that the ontology of physics is not an appropriate ontology for the explanation of economic phenomena. In doing so, I provide a history and overview of physics transfer from the 1870's to the present divided into two historical periods: section 1 summarizes the first period by expositing the work of Jevons, Fisher, and Edgeworth in the period of 1871-1896; section 2 provides a brief overview of the second period, discussing notable econophysical theories from 1971 to the present. As will be shown, the former period witnessed several similar methodological discussions to the latter period and provides a background elucidating contemporary methodological issues in econophysics. Section 3 provides a defense of the two theses with section 4 concluding. 


\section{Physics Transfer in the 19th-century: $1871-1896$}

\subsection{William Stanley Jevons}

Mirowski (1989) advances the widely discussed and provocative thesis ${ }^{2}$ that the concept of 'energy' in mainstream 19th-century physics played a crucial role in how economists of the time rendered economic phenomena: "Neoclassicals did not imitate physics in a desultory or superficial manner...[T]hey copied their models mostly term for term and symbol for symbol" (3). Part of this narrative is Mirowski's attempt to understand the 'neo-energeticists movement': "[T]he conviction that there exists a literal identity between the physical concept of energy and the economic concept of value" $(1988,812)$. A key component of this story is that physicists Michael Faraday and James Clerk Maxwell's conception of forces would heavily influence what is arguably the first major economist to employ calculus in economics and to reason in accordance with explicit analogies from physical theories - William Stanley Jevons (Mirowski 1989, 256-257). That Jevons was the first to use calculus in economics and was a strong advocate of physics transfer makes him a suitable figure to begin our history. ${ }^{3}$

In what follows, it will be sufficient to discuss Jevons's theory of marginal utility and his broader philosophical outlook on the connections between natural and social scientific inquiry. Jevons would define economics as "the causes and effects of man's industry, and shows how it may best be applied," a framework which itself was grounded upon a computation of aggregate pleasure and pain in a community (Jevons 1886, 101). The central idea is that we can construct differential equations, of agents' utility with respect to time, for each agent in the economy, which in turn can lead to enhancing our understanding of equilibria in supply and demand (1871, xxvi). Utility is understood here as a psychological phenomenon of each agent's degree of pleasure or pain derived from the consumption or sale of a good or service. More sophisticated differential equations can be constructed modelling larger social systems containing multiple agents, capturing the dynamics of changes in utility through market exchange. Since he believed that the mental states of agents were unknowable (Jevons 1888 [2010], 2), the best we can do is observe the aggregate behavior of individuals. The economist's role is then to posit imperfect, inductive, probabilistic, economic laws enabling one to reason in accordance with the 'law of large numbers.' This was intended to follow the modus operandi of physics and astronomy, disciplines which historically relied upon analyzing aggregates of data and inferring causal relations $(1886,101)$ :

[E]conomy, scientifically speaking, is...a sort of vague mathematics which calculates the causes and effects of man's industry, and...is analogous to the connection of mechanics, astronomy...and every other branch...of physical science, with pure mathematics.

\footnotetext{
${ }^{2}$ See History of Political Economy (1993) Volume 25, Supplementary Issue 1 for further discussion.

${ }^{3}$ See Mirowski (1984) for more on physics transfer in the 'Marginalist Revolution' period of the latter half of the 19th-century.
} 
Like John Stuart Mill, Jevons understood that conducting experiments in the style of the natural sciences was not practically feasible for studying economic phenomena, given the large and unwieldy number of degrees of freedom of these systems. This made it challenging, and often impossible, to discriminate which causes generate which specific effects. Jevons therefore emphasized the virtues of probabilistic and statistical reasoning for rendering economic phenomena epistemically tractable: "There is really no process of reasoning which enables us to infer from observed to unobserved cases, unless it be the calculus of probabilities" (Jevons 1873, 472). His own work in applying probability and statistics included an investigation into why the planets and their satellites all revolved around the sun in the same direction, predictions of the value of gold, and his famous inquiry into the correlations between sunspot activity and economic activity (Aldrich 1987). For him, the usage of probability and statistics beyond the physical sciences to the analysis of social phenomena was crucial to his view that the sciences were unified: "I believe all the sciences meet somewhere. No part of knowledge can stand wholly disconnected from other parts of the universe of thought" (Jevons 1883, 154). Economics was therefore continuous with natural science: "[T]he theory here given may be described as the mechanics of utility and self-interest...Its method is as sure as and demonstrative as that of kinematics or statics" $(1871,21)$.

In essence, Jevons advocated a positivist methodology with a deductive framework foreshadowing a 'hypothetico-deductive method' of testing hypotheses. Combined with his sympathies for thinking of economic phenomena as akin to astronomical phenomena, both of which he thought were best understood using statistical concepts such as computing 'averages' and 'the method of least squares', Jevons marked the beginning of a more serious commitment to a form of physics transfer, which until the 1870's only witnessed far less radical adherents. As one Jevons scholar argues: "There is almost no question that Jevons regarded mathematics as the means to elevate the scientific status of economics, in direct imitation of the physical sciences" (Schabas 1984, 129; 1990). Physics's usage of mathematics, especially calculus, was persuasive enough in its predictive and explanatory powers that economic phenomena might similarly be discernible through its usage.

\subsection{Irving Fisher on the Conservation of Utility}

While conservation principles were key to the history of physics's development, conservation played a similarly pivotal role in the history of economic thought, with some arguing that it was Hermann von Helmholtz's formulation of the conservation of energy in particular that led to the idea that economic value (exchange and use) was a conserved substance (Mirowski 1989, 142). The conservation of a society's aggregate 'utility', rather than 'money', was a central tenet of Irving Fisher in his republished 1891 dissertation Mathematical Investigations in the Theory of Value and Price (1892). Having been the first recipient of an economics PhD thesis conferred by Yale University, Fisher's connections to physics were deep, with physicist Josiah Willard Gibbs as primary supervisor. Fisher also took inspiration from David Hume's fluid-mechanical models of international specie-flow, among other analogies from hydraulics (Dimand, 
2013). In fact, Fisher took these aquatic metaphors so seriously he took them to be an integral part of his doctoral thesis, devising a 'cistern model' to simulate systems of differential equations for general equilibrium in markets. Concepts and models from physics therefore played key roles in Fisher's work.

To understand Fisher's commitment to fluid mechanical models and a weak form of conservation principle, we first exposit his views on marginal utility. Despite his usage of the word 'utility', Fisher was severely critical of common usages of the concept by his contemporaries. This included not only the 'mental state' accounts of utility in Jevons's writings but also Edgeworth's views in Mathematical Psychics (1881) and the influential writings of psychophysicist Gustav Fechner. Fisher argued against the prevalent methodology of combining empirical psychology with economics, believing that economics must only be concerned with 'positive or objective commodity relations' (Fisher [1892] 1925, 11). Instead, he advocated that we study human desire, as manifested in our revealed and observable preferences when engaging in market transactions, leading to a more objective scientific theory, while leaving the psychology of consumer behavior for psychologists to study (17).

Having abandoned the metaphysics of classical utilitarian views on utility, Fisher's adoption of physical concepts and models begin to multiply. This begins with a discussion in his dissertation of strengths and deficits of using differential calculus in the natural and social sciences: "[T]hese facts do not militate against the use of fluxions for a thinkable theory of forces, density and gaseous pressure...Practically we can find the approximate marginal utility of a commodity...by taking small increments in place of infinitesimals" (22). Stronger physics transfer is present in an explicit table in his dissertation claiming analogical equivalences between the physical concepts of 'a particle', 'space', 'force', 'work', 'energy' and the economic concepts of 'individual', 'commodity', 'marginal utility', 'disutility', and 'utility' (86):

The total work done by a particle in moving from the origin to a given position is the integral of the resisting forces along all space axes...multiplied by the distances moved along those axes.

This remark sits on a table directly across the page from its alleged economic equivalent:

The total disutility suffered by an individual in assuming a given position in the "economic world" is the integral of the marg. disut. along all commod. axes...multiplied by the distances moved along those axes.

While Fisher did not end up constructing an explicit model using the conservation of energy in physics, he did use a model using the conservation of volumes of water in isolated systems via 'cistern diagrams'. These diagrams, prevalent throughout the entire dissertation, are fluid-mechanical models sketched by Fisher so as to represent changes in an individual's marginal utility obtained from commodities' consumption. In doing so, he makes the following assumptions: 
- There is a large enough market $M$ for a commodity such that an individual consumer cannot unilaterally, by adjusting their demand for that commodity, alter the price of that commodity.

- There is a given time period of analysis (e.g. a year).

- The rate of production and consumption in the period are equal.

- Each individual knows all prices in $M$.

- Each commodity is infinitely divisible, thereby justifying the use of differential equations.

- Marginal utility decreases as the amount consumed increases.

A mechanism is then posited along the following lines. Consider a cistern of water as a wooden rectangular prism. The total amount of an individual $I$ 's consumption of a commodity $X$ is modelled by the volume of water that is present in the cistern. Marginal utility is then defined as the remaining empty space in each cistern, in accordance with the idea that marginal utility is diminishing with each subsequent increment in the consumption of the commodity. Each cistern's volume is then altered, either decreasing through leakage or increasing via a pump mechanism, in accordance with a differential equation relating the utility and supply of $X$ as consumed by $I$. In these diagrams, a system of wooden levers represents the content of the differential equations; indeed, Fisher even constructed a real life model using wood and other tools. Since the volume of water is a conserved quantity over time, it would follow for Fisher that one could use elementary conservation laws to describe the dynamics of utility and price in an economy: "The mechanism just described is the physical analogue of the ideal economic market...a clear and analytical picture of the interdependence of the many elements in the causation of prices" (44). Furthermore, equilibrium of utilities is obtained when fluid transfer stops and retains a stable state, rendering his model analogous to stable states of gases in enclosed and isolated systems (86).

At a more macroscopic level, Fisher invites us to imagine a sequence of cisterns interconnected in a large economy in which the water levels of each cistern are regulated by a single 'cistern stopper' (i.e. water pump). This stopper is connected to a sequence of tubes which increase the water levels in each cistern without increasing the total volume and quantity of water in the whole system. The idea here is to model, using a hydraulic analogy, a general increase in consumption in the market for that particular commodity. A conservation principle arises insofar as if we arrange multiple stoppers for multiple markets, commodities, and individuals, then (44-45):

If all the $\mathrm{A}$ cisterns are alike and also all $\mathrm{B}$ cisterns, all $\mathrm{C}$ cisterns, etc., then each commodity will be distributed in equal parts among the individuals...The total money value of the same aggregate commodities in the whole market has increased by the amount of liquid added by depressing the stopper. 
Hence, in his model, there is a significant sense in which the total marginal utility in an economy, as measured by total money, is ultimately conserved through market exchange.

While Fisher believed that utility was a conserved quantity, he nonetheless remained explicit about the limitations of the physical analogies he posited: "The physicist has never fully explained a single fact in the universe. He approximates only. The economist cannot hope to do better" (101). Fisher's theories were an attempt at providing attenuated idealizations for the purposes of explanations and predictions of economic reality. From his perspective, the structural features of economies and physical systems were so similar that not only the successes but even the alleged failures of physics's models held for economic theories: "[T]he actual world both physical and economic has no equilibrium" (104). His usage of the concept of equilibrium was merely intended as a useful idealization for modelling economics, in the same way physicists posit false, but highly useful idealizations (e.g. infinitely smooth planes) in order to derive tractable measurements and results. Fisher therefore disclosed a heightened sensitivity to how idealizations in one's model must be carefully distinguished from their realization in the phenomena being represented.

\subsection{Francis Ysidro Edgeworth on Physics and Scaling Laws}

Contemporaneous with Fisher was Francis Ysidro Edgeworth, the founding editor of The Economic Journal in the same year (1891) Fisher completed his dissertation. Edgeworth would even review Fisher's dissertation favorably with Fisher reciprocating by inviting Edgeworth to lecture at Yale University (Edgeworth 1893; Barbé 2010, 190). Edgeworth read widely, especially in physics: "Fourier's theory of heat, Poisson's mechanics...Clerk Maxwell on physics and, above all else, Laplace on the theory of probability" (Stigler 1977, 290). Edgeworth was also a correspondent of Jevons, often referencing his work (Barbé 2010, 89), with Edgeworth's mother Rosa a close contact of physicist William Rowan Hamilton (36). Following Hamilton's approach to calculating the 'least action' of a physical system, Edgeworth would employ 'the calculus of variations' as a means of finding minima and maxima for equilibrium in market exchange (Edgeworth 1877; 1881).

It is therefore no surprise that Edgeworth was an advocate of physics transfer. He believed that the application of hydrodynamics in fluid mechanics could shed light on (1) understanding the uniformity of price of a commodity in a market; (2) the fact that markets compete to offer the lowest prices while still retaining a profit; (3) that (1) and (2) can be reasoned about via application of the calculus of variations (a common formalism in 19th-century physics) (Edgeworth 1881, 5-6). This idea persisted in his paper 'Rationale of Exchange' (1884, 165):

The field of competition may be compared to...two groups of particles in a plane, each particle tending to its own position of maximum (kinetic, minimum potential) energy...Equilibrium, which is indeterminate in the case of a finite number of particles, becomes determinate in the limit. 
While there is much to comment on Edgeworth's usage of the notion of 'equilibrium in physics', and their analogical relevance to his famous microeconomic theory of indifference curves, my focus is on highlighting seldom discussed statistical methods that Edgeworth employed that foreshadow methodological discussions in contemporary econophysics. These methods are particularly pertinent to Edgeworth's active debates with economist Vilfredo Pareto over the meaning and significance of 'power-law distributions' with respect to a population's income and wealth.

The Edgeworth-Pareto debate on scaling laws occurred during an exchange of papers in 1896 in which Edgeworth published in the Journal of the Royal Statistical Society and Pareto responded in Gionarle degli Economisti. Edgeworth began by arguing that Pareto's attempt to find a universal set of economic properties that are applicable to many societies throughout history is problematic on the grounds that a correlation, even a robust one, is not sufficient evidence of a causal mechanism. While Edgeworth acknowledges that income distributions constitute some form of power law, he argued that a better statistician would discern the relevant structural affinities between correlated variables (Edgeworth \& Pareto [1896] 2008, 425). He notes for example that it would nearly always be irrational to conclude that the letters in a baby's name causally influenced its birth weight, no matter how strong the correlation may be (Edgeworth 1922, 268). Thus what separates a clever scientist from an amateur is their ability to discriminate the relevant causal mechanisms and appropriate structural constraints.

To see how Edgeworth's views on structure play a role in his broader philosophy of science, the focus of Edgeworth and Pareto's debate centers upon a particular class of relations of the following form:

$$
\log (N)=\log (A)-\alpha \log (x)
$$

where $N$ is the number of people who have income $t \geq x$, and $A>0$ a constant. This is equivalent to the following power-law:

$$
N=A x^{-\alpha}
$$

Pareto argued that such curves represent "the law of total incomes...almost the same over an extremely wide range of countries" (Edgeworth \& Pareto, [1896] 2008, 431). Edgeworth largely agrees that the general spirit of the power-law is correct but that "a close fit of a curve to given statistics is not, per se and apart from á priori reasons, a proof that the curve in question is the form proper to the matter in hand" (425).

His reasons are several. First, he notes that this cannot be a literally true formula because "there ought to be an infinite number of null incomes, and an indefinitely [sic] number of incomes in the neighbourhood of zero" (425-426). This objection is straightforward since the function, interpreted literally, has the absurd consequence that an infinity of people are completely destitute and without any income.

Secondly, Edgeworth objected to Pareto's definition of $N$ insofar as taking the integral of $N$ in the following form: 


$$
N(y)=\int_{y}^{\infty} A x^{-\alpha} d x=\infty
$$

would always lead to divergent values for any income $y$ of consideration. However, if we restrict the domain such that $\alpha>1$, then the integral converges and becomes definite. Edgeworth's complaint here is that it is not enough to consider the specific domain in which the integral has convergence, since any adequate mathematical law of nature or society ought to account for even highly unusual values of the parameters. If a social scientific law was ever to be as rigorous as a physical law, then it should admit few, if any, exceptions. Pareto objected that there is nothing conceptually problematic about restricting the domain of any given equation to a narrower set of values in order to derive empirically meaningful results. Edgeworth rebutted that even so, a different class of distributions would not only be more satisfying from an a priori perspective but would fit the facts of empirically observed data, such as 'housing valuations', more accurately than Pareto's curves (426).

Thirdly, and here is where the analogies from physics enter in full force, Edgeworth argued that what is true of natural phenomena is more likely to also be true of social phenomena. He believed that insofar as probability density functions can be used in physics to model the velocity of moving bodies, such functions are also able to model 'house values' and 'amounts of income' as well (428). The thought here is that such distributions are highly accurate in physics and therefore likely to be applicable beyond the confines of physical theories too, so long as the right structural conditions hold. Such structural conditions were important as they illustrated a hypothesized underlying mechanism for the phenomenon being observed. Entertaining the idea of a 'universal frequency curve' of the form ${ }^{4}$

$$
y=\frac{1}{\sqrt{x c}} \exp \left(\frac{-(x-a)^{2}}{c^{2}}\right)
$$

where $a, c$ are real numbers, he comments that it is "a law which is known to be applicable to the most diverse subjects, not only empirically by observation, but also a priori by mathematical theory," emphasizing this curve's a priori derivation from a proposition similar $^{5}$ to the Central Limit Theorem (438). Pareto objected that such a distribution would similarly have to be truncated by imposing restrictions on its parameters, to which Edgeworth would reply that at least such a distribution would no longer be ad hoc since it was based upon first principles of pure mathematics.

Another physical analogy arises in this debate when Edgeworth describes, as an exemplary case of the harmony of a priori reasoning and empirical confirmation, Newton's demonstration of the planets in the solar system as elliptical in orbit, cohering with Johannes Kepler's own observational data (425). In this sense, their exchanges in 1896 illustrated how Edgeworth's standards of evidence were stricter than Pareto's when it came to the empirical confirmation of a mathematical theory of economic phenomena,

\footnotetext{
${ }^{4}$ ' $\exp (x)$ ' refers to $e^{x}$, where $e$ is Euler's number.

${ }^{5}$ Notice that this is not a Gaussian distribution.
} 
given that satisfactory a priori reasoning and empirical confirmation were both required of an adequate economic theory. Nonetheless, both were attentive to the extent at which economic analysis needed to be conducted with careful attention to whether the relevant structural conditions obtained when importing models from physics into economics.

In summary, 19th-century physics transfer was characterized by careful methodological reflection on the scope and limits of drawing upon the physical sciences as a guide to economic inquiry. Several related themes in their work continued a century later in the modern interdisciplinary field of econophysics to which we now turn.

\section{Modern Econophysics: 1971 - Present}

\subsection{The Rise of a Chimera: Mathematical Methods and Models from Physics}

A chimera of a discipline, econophysics evades easy definition with its only plausible methodological unity residing in its attempted explanation and prediction of economic phenomena using concepts, models, and methods in physics. First coined by physicist H. Eugene Stanley in 1995 at a conference in Kolkata, ${ }^{6}$ 'econophysics' is a heterodox and yet increasingly active ${ }^{7}$ field with several standalone monographs published by respected university presses such as Cambridge (Mantegna \& Stanley 2004) and Oxford (Jovanovic \& Schinckus 2017). A portmanteau of 'economics' and 'physics', econophysics exhibits an explicit commitment to physics transfer, positing strong analogies and conceptual transfer from the methodologies of mainstream physics to the study of economic phenomena. Econophysicists proclaim such relationships as log-periodic power laws in condensed matter physics for the analysis of stock market crashes and the BoltzmannGibbs distribution for the monetary dynamics of wealth inequality. Thermodynamic entropy, Shannon information, Kolmogorov complexity theory, and even the 'labor theory of value', coalesce into a vast nexus of models constituting econophysical theories (Cockshott et al. 2009).

Unlike economist Paul Samuelson's description of general equilibrium analysis as a form of comparative statics analogous to equilibrium reasoning in physics $(1947,8)$, or economist Walter Isard's 'gravity model of trade' (1954), most econophysical theories do not employ concepts from physics merely metaphorically. Rather, concepts from physics simultaneously guide, shape, and in some cases provide the literal content of entire theories, and are intended to have interpretations closely mirroring the mechanisms of their initial application in physical contexts. In this sense, one might suggest that Georgescu-Roegen's (1971) The Entropy Law and the Economic Process marks the first major econophysical work of the 20th-century, one which defends the application of thermodynamics for the study of economic phenomena. New computer simulation technology and data collection methods have also led to the rise in interest by physicists

\footnotetext{
${ }^{6}$ Cited in Sinha \& Chakrabarti $(2012,46)$.

${ }^{7}$ Since at least as early as 2006 , the University of Houston has launched the first PhD program in the United States for the study of econophysics. The East China University of Science and Technology also has a Research Center for Econophysics using methods from physics to understand high-frequency trading data (Yu \& Li 2010).
} 
in economic and financial phenomena (Kutner et al. 2019, 241). Econophysicists also claim that their models are more empirically accurate, and have greater predictive power, than models in contemporary economics and finance (McCauley 2006; Rickles 2007, 954957). Econophysics therefore promises a cornucopia of predictions and explanations that orthodox economics allegedly cannot deliver upon.

Despite its increasing prominence, understanding the discipline's influences and methodological assumptions is sociologically and historically challenging for several reasons. Firstly, it has been claimed that econophysics currently is, and often was, a 'relative autarchy' (Gingras \& Schinckus 2013). This is so to the extent that its conferences, journals, and communities have been moored on scholarly islands remote from the mainstream practices of both physicists and economists. Indeed, much of econophysics has been systematically criticized for misapplying the methods of physics for studying financial market phenomena (Rickles 2007). Others emphasize a mutually positive state of disciplinary transfer: "Econophysics seeks not to displace economics, rather it aims to help economists find deeper understandings of complex systems with a large number of degrees of freedom" (Richmond et al. 2013, 17). Furthermore, there are econophysicists who have argued strongly against mainstream economics making efforts at dialogue challenging: "[A]ll existing 'lessons' taught in standard economics texts should be either abandoned or tested empirically, but should never be accepted as a basis for modelling" (McCauley 2006, 603). Despite contributing significantly to the field of mathematical finance, "dialogue between econophysicists and financial economists is almost nonexistent" (Jovanovic \& Schinckus 2017, x). Econophysicists can therefore sometimes appear as unwanted but well-intentioned strangers knocking at scholarly communities' doors hoping to mitigate long-standing dogmas in financial economics, such as dogmatic belief in the 'efficient market hypothesis' and an overly strong reliance on Gaussian distributions.

Secondly, many have claimed that econophysics's methods are in a significant sense historically unprecedented. Some have argued that there is bibliographic evidence that econophysics did not become a significant sub-discipline of either economics or physics until the late 1990's, as elicited from data from the journal Physical Review E (published by the American Physical Society) in which the term 'market' does not appear in this journal until 1999, the term 'physics' not appearing in Econometrica until 2001, and the term 'econophysics' until late 2005 (Sinha \& Chakrabarti 2012, 45). Others agree and emphasize that "econophysics is supposed to be something novel" (Rickles 2007, 951).

Thirdly, other narratives suggest that econophysics is not even part of the history of economic thought in a conventional sense. For instance, while Weatherall (2013) focuses on the usage of several econophysical models in some Wall Street firms' investment strategies, such as the work of former physicist and mathematician James Harris Simons at his hedge fund Renaissance Technologies, he largely ignores figures in the history of economic thought. Similarly, Jovanovic \& Schinckus (2013) argue that econophysics is best understood as "the extension of physics to the study of problems generally considered as falling within the sphere of economics" suggesting a closer affinity to the history of physics than that of economics (445). They further claim that econophysics, as has 
been practiced from the 1990's onwards, has been almost entirely the purview of physicists publishing in journals such as Physica $A,{ }^{8}$ in their attempts to study social science problems, rather than publications by academic economists. Econophysics has recently been argued to be taken especially seriously in Chinese academic communities with Beijing Normal University, Peking University, and Fudan University considered prominent institutions in this regard (Schinckus 2018, 618). As a recent systematic review notes: "[A] number of renowned physicists had an instrumental role at that time in getting approved econophysics by editorial boards of such significant physical journals as Physica A, The European Physical Journal B, and the International Journal of Modern Physics C. Currently, almost all major physical journals already accept econophysical works" (Kutner et al. 2019, 241). However, even amongst physicists, econophysical ideas have not been uniformly well received, with one econophysicist, on who is incidentally employed in a physics department, recounting: "This paper was also originally submitted to Physical Review Letters and received generally positive referee reports, but was still rejected on the grounds that 'it is not physics'....Reviews of Modern Physics accepted the paper...albeit not without a fight with referees." (Yakovenko 2016, 3316).

These sociological complexities aside, what nonetheless remains clear is the discipline's indebtedness to the strongest forms of physics transfer in the history of economic thought so far. Many contemporary econophysicists see econophysics as simply an extension of physics, with goals towards unifying the natural and social sciences. For instance, some have compared fluctuations of the S\&P 500 Index with models of turbulence in fluid mechanics, defending strong analogies between these types of systems (Mantegna \& Stanley 2004, 88-97). Others have argued for the field's continuity with physics: "[I]n the period following a large crash, markets show lingering activity which follows the famous Omori law for earthquake aftershocks" (Buchanan 2013, 317). Near universally, contemporary econophysicists consider probability, statistics, and inductive methods central to their methods, eschewing deductive and a priori theorizing. This contrasts heavily with the history of mainstream neoclassical economics of the 20thcentury which privileged a priori reasoning and deductive models (Hutchison 1998). Econophysicists jettison many of the idealizations and axiomatic approaches of neoclassical economics and instead advocate a strong form of neo-positivism, bordering on the ad hoc. Central to this neo-positivism is the empirical finding that price changes exhibit probability distributions that have higher kurtosis values than is predicted by a standard Gaussian distribution, entailing that extreme changes in price are much more likely than mainstream mathematical finance theorists claim. This is because mainstream finance theorists often posit distributions with a 'kurtosis around zero' as contrasted with econophysicists' positing of leptokurtic distributions (Schinckus 2010, 2817). A diversity of assumptions, methods, and models are employed, several popular ones of which we now survey in what follows.

\footnotetext{
${ }^{8}$ The percentage of articles with the term 'econophysics' in Physica A began as low as 0\% in 1996 and increased to highs of $18 \%$ in 2004 and $20 \%$ in 2007, with a modest upward trend between 1996 2009 (Jovanovic \& Schinckus 2013, 448).
} 


\subsection{Econophysics: Conservation Principles}

Conservation principles are among the most common concepts in contemporary econophysics (Richmond et al. 2013, 220; Slanina 2014, 128-129). Before we articulate their content, consider first the concept of labor, understood as the physical energy exerted by the human body for the purposes of altering one's environment for a pre-specified task. From John Locke's argument that nature is one's property whenever one mixes their labor with it, to Karl Marx's defense of the 'labor theory of value', labor has been central to economic theory. Being a physical phenomenon, several econophysicists have claimed that labor is therefore alleged to be related to the concepts of 'work', 'energy', 'entropy', and 'information' in physics (Cockshott et al., 2009). Unlike Smith or Marx, such a view is not one of mere analogy but is taken to be an attempt to literally construe physical labor in terms of physical energy and information. This includes transferring not only the mathematical formalism but, more strongly, the mechanistic content of physical theories which use concepts such as the conservation of energy.

Along these lines, Viktor Yakovenko describes the birth of his econophysical ideas as an undergrad studying in Moscow in the late 1970's learning statistical mechanics (Yakovenko 2017, 3314):

"While conservation laws in physics follow from fundamental space-time symmetries, conservation of money is the law of accounting...I thought of the economy, which is surely a big statistical ensemble with millions of interacting agents. But is there a conserved variable?...Ordinary economic agents can only receive and give money to other agents, but are not permitted to "manufacture" money. (This would be criminal counterfeiting).

To understand this idea, consider the following simplified model. Let $N$ be the number of people in a finitely populated economy. Each person $p_{i}$ of the economy has $m_{p_{i}}$ amounts of money. Let $M=\sum_{i=1}^{N} m_{p_{i}}$ be the sum total of all money in the economy. Suppose that everyone in the economy initially has the same amount of money (i.e. $M / N$ ). Now assume that the following dynamics apply to this economy where a single iteration of the system involves:

(1) Randomly picking two actors (one buyer, the other seller) where each has the same probability of having a given role.

(2) Randomly picking a price $p$ for the transaction within the interval $[0, x]$ where $x$ is the total amount of money of any given buyer.

(3) The buyer's new money amount is $x-p$ after the iteration is complete.

Yakovenko's claim ${ }^{9}$ is that such a process, if iteratively applied, follows a BoltzmannGibbs distribution: ${ }^{10}$

\footnotetext{
${ }^{9}$ See Cockshott et al. (2009), section 7.1.1, for further discussion.

${ }^{10}$ Here, the symbol ' $\propto$ ' is to be understood as 'proportional to'.
} 


$$
P\left(m_{p_{i}}\right) \propto \lambda \exp \left(-\lambda m_{p_{i}}\right)
$$

That is, the probability of person $p_{i}$ having the amount of money $m_{p_{i}}$ is proportional to an exponential function of the amount of money, for $\lambda$ a positive real number. The intuition extrapolated from here is that the probability that someone has a lot of money is lower the higher the amount of money.

Yakovenko takes the physical analogy seriously enough to ground his economic theory upon the causal mechanism of entropy in statistical mechanics, and hence is not merely borrowing the mathematical framework of the Boltzmann-Gibbs distribution but its physical interpretation as well. In this sense, Yakovenko's usage of conservation principle reasoning is more ambitious in its physics transfer than the more modest usage of conservation reasoning present in Fisher's 19th-century cistern model.

\subsection{Econophysics: Scaling Laws}

Scaling laws of the form $Y=a X^{\beta}$, for $Y$ a dependent variable, $X$ an independent variable, and $\beta$ the power law exponent, have been defended as the closest candidate for the existence of non-trivial laws in contemporary economics (Gabaix 2016). Jovanovic \& Schinckus $(2013,451)$ argue that the most salient concept heralding the rise of econophysics as a separate discipline is the usage of 'stable Lévy processes' of the form $P(X>x)=x^{-\alpha}$, with $\alpha$ a positive real number and $X$ a random variable (e.g. a stock's price). What is methodologically significant about Lévy processes is that they can be constructed so as to be stable (time invariant), have infinite variance, and yet can be used to accurately model the dynamics of stock market pricing.

One way in which contemporary econophysicists have applied scaling laws in novel ways is in their articulation of the purported 'scale invariant' properties of market systems. Scale invariance involves the property of a physical system exhibiting self-similarity in structure at differing scales of analysis. For instance, building upon the work of Johansen et al. (2000), Jhun et al. (2018) have argued that what they call the JohansenLedoit-Sornette (JLS) model can predict the spontaneous, yet endogenously arising, actions of financial actors in stock market crashes (Sornette 2014). These include the US 1929 and 1987 crashes, and the Hong Kong crash of 1997. This model is explicitly based upon reasoning used in models of critical phase transitions in modern physics.

Firstly, the model assumes that assets are purely speculative, as it pays no dividends, and constitutes an explicitly false but allegedly useful idealization of market prices (Johansen et al. 2000). Secondly, part of the model posits a martingale assumption according to which for an asset with price $p(t)$,

$$
\forall t^{\prime}>t \quad E_{t}\left[p\left(t^{\prime}\right)\right]=p(t)
$$

where $E_{t}$ is the conditional expectation on information up to a time $t$. Thirdly, define $Q(t)$ to be the cumulative distribution function of the time of the crash, and hence $q(t)=d Q / d t$ is the probability density function with hazard rate $h(t)=q(t) /[1-Q(t)]$. The hazard rate is intended to be interpreted as "the probability per unit of time that 
the crash will happen in the next instant if it has not happened yet" (Johansen et al. $2000,223)$. Fourthly, define $j$ to be a binary variable that takes on the value 0 for all times prior to the crash and a value of 1 for all times at and after the crash. Fifthly, the instantaneous rate of change of a price $(d p)$ can be understood as obeying the form

$$
d p=\mu(t) p(t) d t-k p(t) d j
$$

for some time-dependent drift parameter $\mu(t)$ that satisfies the martingale condition in the second assumption; that is, $E_{t}[d p]=\mu(t) p(t) d t-k p(t) h(t) d t=0$, which yields $\mu(t)=k h(t)$. Lastly, we solve and rearrange terms to arrive at the following log-periodic power law:

$$
\log \left[\frac{p(t)}{p\left(t_{0}\right)}\right]=k \int_{t_{0}}^{t} h(t) d t
$$

Here, $t_{0}$ is a stipulated initial time, $p(t)$ the price at some later time $t$, and $k \in(0,1)$ represents the drop in price of the asset by some percentage.

The relationship to mechanisms in physics is as follows. Assuming that traders' market interactions are representable as a lattice framework, the 'Ising model' of phase transitions in paramagnetic-ferromagnetic phenomena is posited as a strongly analogical model. These phase transitions have been modelled successfully as early as the 1920s in the work of Whilhelm Lenz and Ernest Ising, and later culminated in 'renormalization group methods' in the work of Nobel laureate Kenneth Wilson, ${ }^{11}$ of which the JLS model builds upon (Wilson 1979). In physical systems, one defines the 'susceptibility' of the system to be a variable $\chi$ defined as: ${ }^{12}$

$$
\chi \approx A\left|T-T_{C}\right|^{-\gamma}
$$

with $A$ a positive real number, $T_{C}$ the critical temperature (i.e. the Curie temperature), and $\gamma$ a critical exponent. This represents the propensity for particles in magnets near one another to mimic one another's spin behavior as the temperature decreases. Instead of spin measurements (i.e. up or down) being correlated in physical systems, whether a trader decides to purchase or sell a financial instrument is the binary variable of interest in the econophysical context. ${ }^{13}$

Hence, the JLS model claims analogously that stock traders behave in accordance with the following equation:

\footnotetext{
${ }^{11}$ It is worth noting that Wilson was the $\mathrm{PhD}$ supervisor of Belal Baaquie, who is a notable contemporary econophysicist active in applying the mathematical formalisms, but not mechanisms, of quantum field theory for application in financial modelling (Baaquie 2004; 2018). Baaquie's work is nonetheless criticized at length in Arioli \& Valente (2021) for misapplying several key formalisms.

${ }^{12}$ Here, the symbol ' $\approx$ ' is to be understood as 'approximates to'.

${ }^{13}$ This at least is the charitable interpretation of the JLS model. In the original paper, Johansen et al. (2000, 220) write: "The individual trader has only 3 possible actions (or "states"): selling, buying or waiting." However, this would render their model strongly disanalogous to the physical systems they are inspired by, as the spin of ferromagnets in physical models have only two possible states (up and down).
} 


$$
h(t) \approx B\left|t-t_{c}\right|^{-\alpha}
$$

with $t_{c}$ the most probable time of a crash and $B, \alpha$ positive real numbers, rendering it a scaling law whose structure is reminiscent of the kind posited in the Edgeworth-Pareto debate. Since asset prices are particularly volatile as they approach $t_{c}$, the following complex-valued equation is claimed to be a better approximation of $h(t)$

$$
h(t) \approx\left(\beta_{0}\left|t_{c}-t\right|^{-\alpha^{\prime}} \beta_{1}\left|t_{c}-t\right|^{-\alpha^{\prime \prime}} \log \left|t_{c}-t\right|\right)+\psi
$$

where $\alpha^{\prime}, \alpha^{\prime \prime}$ are the real and imaginary parts of $\alpha$ respectively, and $\beta_{0}, \beta_{1}, \psi$ real constants (Jhun et al. 2018, 4486).

Where does scale invariance come in? The key claim here is that the critical exponent $\gamma$ in the physical equation $\chi$, and the critical exponent $\alpha$ in the hazard rate equation $h(t)$, is one that has a very similar value to that of other equations governing physical phenomena at different scales of analysis. Analogously, the different levels of scale of market participants acting during a single market crash are all supposed to exhibit similar trading behavior upon approaching the critical time $t_{c}$.

To understand the more general analogy with physics, note that a wide variety of physical systems exhibit scale invariance properties. Given the value of some quantity $v(Q)$ such that

$$
v(Q) \sim\left|T-T_{c}\right|^{p}
$$

where $p$ is the critical exponent, $p$ has a remarkably similar value despite changes in the scale of the phenomena it is concerned with. $v(Q)$ 's scaling properties can be illustrated through several examples (Bouatta \& Butterfield 2014, 33):

(i) $Q=\rho_{\text {liquid }}-\rho_{\text {gas }}$, the difference between the densities of liquid water and steam.

(ii) The average magnetization $Q=m$ of a piece of iron.

(iii) $Q=-\frac{\partial V}{\partial p_{T}}$, measuring the isothermal compressibility of water at fixed temperature $T$.

(iv) $Q=-\frac{\partial m}{\partial B_{T}}$, measuring how iron's magnetization changes as a function of an externally applied magnetic field $B$.

Each pair (i) and (ii) both witness the same precise value of $p \approx 0.35$. Similarly, (iii) and (iv) have the same value of $p \approx 1.2$ This is so despite these phenomena being different in their physical properties and with respect to their scale, since (i) and (iii) are more macroscopic in size compared to the more quantum behavior of (ii) and (iv). 


\section{Assessing Physics Transfer in Econophysics}

Having surveyed prominent cases of 19th-century physics transfer and several modern econophysical models, I will now argue for the following two claims:

- Transferring mathematical methods from physics into economics is justified only if such methods yield empirically adequate models. A model is empirically adequate when it either (i) predicts some future set of events or (ii) makes claims which cohere with data on past events, such as time-series analyses. Since econophysical models are frequently empirically adequate, econophysical methods are therefore justified in transferring mathematical methods as such.

- The application of mechanisms from physics to the study of economic phenomena is often unjustified, given that the ontology of economic reality is distinct from that of physical reality, rendering physical explanations of economic phenomena inadequate.

The first of two subsequent sections articulates an account of mathematical method transfer that demonstrates how several mainstream econophysical models featuring such methods are often empirically adequate. The second section provides a systematic analysis of mechanisms in economics and the ways in which econophysical mechanisms typically do not obtain.

\subsection{The Status of Mathematical Transfer}

Evaluations of interdisciplinary method transfer, such as the usage of mathematics in one discipline for usage in another, require close attention to how exactly a mathematical formalism is used in the historically situated context. This raises questions as to what conditions need apply for the transference of mathematical methods from one field to another to be justified.

We can draw upon a related analysis from Bradley \& Thébault (2019) and make a distinction between 'migration' and 'imperialism' of models. Migration concerns model transfer that involves changes in intended representational function; imperialism concerns the extension of a source theory's model of one phenomenon to the analysis of a distinct phenomenon, without significant change in the representational structure. The latter requires a much higher standard to be considered justified than the former does. Analogously, we can claim that the transference of mathematical methods in field X to field $\mathrm{Y}$ is migratory if the transfer does not entail significant revision in terms of the kinds of phenomena it is intended to be applied to; transference is imperialistic only if there are significant changes in representational function.

For example, there was innocuous usage of differential calculus, a technique originally developed in 17th-century mathematical physics, for the application of microeconomic formalism in the pioneering work of Jevons ([1871] 1970); this is an example of migratory mathematical transfer. Here, differential calculus was used to study maximization and 
minimization problems in physics and were similarly used in the context of microeconomics of the late 19th-century, continuing into the present day. As another example, the method of 'null-hypothesis statistical testing' (NHST) was used in astronomy at least as early Pierre Simon Laplace's 19th-century calculation of the low probability 'due to chance' that all forty-three planets and their respective satellites revolve in the same direction around the sun (Aldrich 1987, 239). And yet, NHST has found widespread applicability in agriculture, medicine, economics, psychology, and most other modern sciences. Regression analysis began at least as early as 1805 in the 'least squares' calculations of Adrian Legendre, improving extant efforts to determine the positions of celestial bodies (Stigler 1986, 12-15). Nowadays, regression modelling is nearly synonymous with econometrics (Woolridge 2019). By way of contrast, an example of imperialistic mathematical transfer would be the application of decision theory, originally developed in microeconomics, for usage in the Everettian interpretation of quantum mechanics. Decision theory's mathematical formalism was initially developed for calculating the expected utility of a single agent taking a single action with uncertain outcomes in a single world and yet has been used by some Everettians for usage in the context of branching worlds "with things that happen to individual future copies of the agent, on particular branches" (Greaves 2007, 114). This is a radically different context of usage than normal decision theoretic scenarios given that in Everettian contexts, individual agents are duplicated, and yet the mathematical formalism's content is preserved from the economic context into the physical context. In both cases mathematical transfer occurs between two distinct fields analyzing distinct phenomena.

There are two lessons to learn from this history that concern our present discussion. The first is that, as in the history of physics, we ought not impose any particular normative boundaries on a discipline's internal attempts to formulate a diversity of mathematical formalisms for the same phenomena. It is plausible that there may be no historically invariant set of epistemic criteria that can demarcate when an active diversity of mathematical frameworks within a discipline is fruitful and when it is epistemically deficient. The sole, weakly restrictive, standard should be that a mathematical formalism is justified in being transferred, from a source to a target discipline, only if it is empirically adequate with respect to its newly intended domain. Any stronger criteria would risk stifling potentially useful method transfer for explanatory and predictive purposes.

The second lesson is that the same criteria may arguably be applied in the evaluation of external transfer of mathematical methods from a source field to a distinct target field. In this sense, 19th-century physics transfer advocates such as Jevons, Edgeworth, and Fisher were justified in migrating mathematical methods from physics in their efforts to unify the social and physical sciences. Jevons was motivated by an 'optimistic meta-induction argument' that the success of astronomers' abilities to discern the behavior of cosmic phenomena, using statistical methods, could help understand and predict economic phenomena. However, he did not believe that the ontology of physics was supposed to transfer to economic systems. At the level of model transfer, Edgeworth was modest in arguing that the volatility in the velocity of gas particles was only ana- 
logically similar, in terms of mathematical modelling, to the volatility of housing prices and wealth inequality. While Fisher may appear to be an imperialist, given his commitment to conservation principles in the cistern model, he was aware of the limitations of such models, emphasizing that they were only idealizations and not to be interpreted literally. In both Edgeworth and Fisher's case, each borrowed, respectively, the methods of 'the calculus of variations' and 'vector calculus', from physics for application in economics, without also transferring the mechanisms from physics that such methods typically articulate the content of (e.g. the principle of least action).

In a similar vein, many modern econophysical theories are justified in their usage of the mathematical formalisms of physics at the level of migratory mathematical transfer. In 1863, Jules Regnault introduced the now pervasive random-walk models used in finance, inspired by the physics of Brownian motion, with some historians noting that "[he] defended his thesis in a field called at this time mathematical physics," with many of these models providing accurate predictions of the volatility of financial instruments (Jovanovic \& Schinckus 2017, 4). Baaquie (2004; 2018) claims that forward interest rates for treasury bills may be modelled mathematically via formalisms used in quantum field theory given that the latter's usage of 'Feynman path integrals' can adequately model the high degrees of freedom present in the former, while insisting that such a model is merely analogical. Here, the claim is that mathematical methods used in quantum physics may be applied to analyze distinct phenomena, such as financial markets. ${ }^{14}$ Jovanovic and Schinckus $(2017,28)$ argue that the company IBM's daily log stock returns from July 1962 until December 1998 are significantly better predicted using a leptokurtic probability distribution than are the Gaussian distribution models used in mainstream economics and finance. Such methods were historically based upon mathematical models used in physics, such as 'stable Lévy processes and power laws' in statistical physics, as in the work of Mandelbrot (1962). More recently, fractional-order models utilizing differential equations with derivatives of non-integer order, as in the physics of anomalous diffusion phenomena, have also been argued to be an effective means of predicting NASDAQ and Dow Jones index closing values, using a data set running from 1928 - 2009 (Duarte et al. 2009; Tarasov 2020). The distribution of income of societies as far ranging as ancient Egypt to 19th-century Europe and contemporary Japan exhibit a mathematical structure mirroring the Gibbs distribution from statistical mechanics (Sinha \& Chakrabarti 2012, 53). Leng \& Li (2020) analyze fluctuations in crude oil prices using a measure of information entropy in order to estimate the 'entropy', that is uncertainty, of pricing in the global crude oil market.

In these cases, it is only a mathematical method, and not a mechanism, from physics that is being applied in an economic context. In each example, these econophysical theo-

\footnotetext{
${ }^{14}$ However, even on this point, Baaquie's work has recently been criticized by Arioli \& Valente (2021) for inappropriately applying quantum field theory's mathematical formalism, specifically with respect to the usage of imaginary units in the Schrödinger equation, given that 'interference phenomena' do not exist in finance in the way this occurs in the quantum realm. And yet, these authors agree with my analysis that "what helps one justify the empirical success of quantum econophysics is just the fact that the applied models lose some of their characteristic quantum-mechanical components" (Arioli \& Valente $2021,3)$.
} 
ries are claimed to be empirically adequate, and some are even more so than mainstream financial theories. ${ }^{15}$ Given these examples, it is plausible to believe that the only criteria for justifying either migratory or imperialistic mathematical transfer should be whether or not the mathematics used from the source discipline for purposes in the target discipline generates empirically adequate models. While one may legitimately attempt to contest the empirical adequacy of such models, any lasting prejudices concerning ostensibly radical cases of mathematical formalism transfer are arguably unjustified if such methods can deliver accurate and useful predictions.

\subsection{The Status of Mechanistic Transfer}

That econophysical theories employ mathematical methods that typically lead to empirically adequate models is not to be confused with the extent at which econophysical models positing a physical ontology, more specifically mechanisms, are justified. We follow recent work in the philosophy of models and define a model as a representation of the world which serves as a 'functional entity' providing a more epistemically tractable surrogate system representing a target system (Gelfert 2016, 26). Models are more epistemically tractable than the real world target systems they represent given that models typically contain a combination of abstractions (omissions of known features of the target system) and idealizations (the introduction of fictions known to depart from observed properties of the target system), and are introduced to ease calculations, make predictions, and enhance overall intelligibility of the target system.

The most salient feature of models in econophysics, and in physics and economics more generally, is the presence of mechanisms. Discerning the extent at which the application of mechanisms of physics is justified in economics requires a distinct set of evaluative criteria from that of mere mathematical model transfer. We follow a mainstream account and define mechanisms as "entities and activities organized such that they are productive of regular changes from start or set-up to finish or termination conditions," with distinct parts of the mechanism interacting with one another in intelligible ways (Machamer et al. 2000, 3). Mechanisms, especially in social reality, are furthermore to be understood in the context of our discussion as theoretical, unobserved constructs that connect observable social entities with one another in certain specified relations posited by models (Hedström et al. 1996, 290). Furthermore, positing an appropriate ontology of mechanisms is arguably required to establish causal claims (Russo \& Williamson 2007; Marchionni \& Reijula 2019). ${ }^{16}$

Given these definitions, many econophysicists frequently engage in imperialistic model transfer at the level of mechanisms and yet are unjustified in doing so, for at least the following seven reasons:

(1) Many purported econophysical mechanisms are not mechanistically transitive.

\footnotetext{
${ }^{15}$ See chapter 5 of Jovanovic \& Schinckus (2017) for further examples.

${ }^{16}$ See also Kincaid (2021) for a recent systematic overview of how diverse conceptions of mechanisms remain in economics and the social sciences.
} 
(2) Many econophysical models positing mechanisms do not provide sufficient details on the socially constructed elements of financial phenomena, such as the role banking regulations (or lack thereof) play in financial crises.

(3) Many econophysical models do not provide sufficient details as to the exact parts and boundaries of the mechanisms they posit.

(4) Econophysicists do not agree on what constitutes an equilibrium state of a system.

(5) Econophysicists do not have a clear conception of how time functions as a variable in their theories.

(6) Many econophysical models do not provide a clear account of the ways in which econophysical mechanisms may be intervened upon.

(7) Many econophysical experiments are not, contra advocates, controlled experiments but psychology experiments, and hence cannot be used to find causal mechanisms in economic reality in analogy with physical experiments.

Subsequent sections of the paper will provide further detail on each respective reason listed above.

\subsection{Issues with Mechanistic Transitivity}

Firstly, mechanistic transitivity is to be understood in the following sense: if $X$ is a mechanism for $Y$, and $Y$ a mechanism for $Z$, then $X$ is a mechanism for $Z$. For instance, in social reality, cigarette advertising might plausibly be a transitive mechanism for lung cancer insofar as such advertising promotes the consumption of cigarettes which in turn causes lung cancer. Mechanisms in physics are typically transitive in their downstream causal effects, such as quantum mechanical phenomena occurring for not only microscopic but macroscopic systems. However, it is implausible to think that physical mechanisms are mechanistically transitive with respect to economic phenomena. As argued by Machamer et al. (2000, 3), high quality hypotheses about mechanisms arguably need to exhibit 'productive continuity' between stages from initial conditions to terminating conditions. Mechanisms that occur in physical contexts do not plausibly hold of economic contexts, even if it might be true that social processes supervene upon physical processes, rendering invalid the plausibility of productive continuity.

To clarify, there ought not be an expectation that mechanisms posited in one science must be mechanistically transitive for all phenomena which supervene upon it, as this is an implausibly strong criteria to expect of scientific theorizing. Rather, what makes many econophysical mechanisms in particular problematic is the claim that purported physical mechanisms are mechanistically transitive for systems that supervene upon it, such as economic ones, when they arguably are not. Indeed, the JLS model at best uses scaling law behavior in the physics of critical phase transitions as a structural analogy for market crashes and does not succeed in illustrating a continuity of mechanism. That is, it is implausible to believe that market crashes exhibit phase transition behavior beyond 
analogy; we have at most a correlation without an explanatory mechanism, bringing to mind Edgeworth's criticisms of Pareto's power-law distribution. This is especially so given that JLS advocates Jhun et al. $(2018,4488)$ explicitly acknowledge that market crashes throughout history are not part of the same 'universality class' of similar critical exponents. Others arguably fail to even understand the relevant physics, such as the claim that: "Economic science may also have a type of Heisenberg inequality, because some microeconomic parameters (like utility) are not observable directly" (Yegorov 2007, 150). Nothing even approximating the relevant mechanism behind Heisenberg's uncertainty principle is present in social reality, as Yegorov misunderstands the sense in which Heisenberg's inequality represents more than a mere inability to 'observe something directly'. ${ }^{17}$ Here, the quantum phenomenon of uncertainty about an observable does not transitively apply to macroscopic economic behaviour as there is no sense in which there are conjugate observables in economics in the ways there are in quantum mechanical phenomena (e.g. position and momentum). Similarly, the crucial assumption of the alleged conservation of money in an economy, in Yakovenko's (2017) BoltzmannGibbs model, is a spurious mechanism. Unlike the conservation of energy, a fundamental empirical finding of modern physics, the conservation of money is an empirically false premise, constantly violated by the existence of criminal counterfeiters and Keynesian macroeconomic stimulus policies. Without this assumption of conservation, the transfer of mechanism from physical to economic systems would be fallacious and mere analogy at best (Thébault et al. 2018).

Problems regarding mechanistic transitivity raise significant doubts for the methodological optimism of econophysicists who believe that economic phenomena may be understood as simply an extension of physical phenomena, where physical theories could eventually wholly explain economic phenomena: "Econophysicists[']...pioneering models are microscopically realistic...and are physically well founded by providing basic mechanisms for the phenomena...Econophysics will become more and more a translation of statistical physics into real individuals and economic reality" (Sãvoiu \& Andronache 2013, 93). As another example, while Rosser (2016) acknowledges the limitations of such a view, he nonetheless concludes: "Entropy can be seen as an ontological driving force of economies, especially as one recognizes their profound reliance on ecosystems driven by solar energy, both current and stored, with this energy dissipating through the system as an inexorable working out of the Second Law of Thermodynamics as described by Georgescu-Roegen" (3101). The introduction of Georgescu-Roegen's landmark 1971 econophysical text exhibited a clear commitment to mechanistic transitivity early in the text: "[T]he Entropy Law is only an aspect of a more general fact, namely, that this law is the basis of the economy of life at all levels" $(1971,4)$. In a recent systematic review of experimental econophysics, we have yet again: "[T] he aim of econophysicists could be...to broaden the realm of traditional physics...the physics that is used to study

\footnotetext{
${ }^{17}$ Two mainstream economists Smith \& Foley $(2008,27)$ make a related criticism concerning attempts to relate economic utility to physical concepts: "The most direct way to understand why utility cannot be a counterpart to energy is to recognize that energy, along with volume or other conserved quantities, defines the surface of possible configurations of aggregated systems."
} 
the nature with non-intelligent units like atoms, rather than the society with intelligent units like humans)" (Huang 2015, 4).

\subsection{Issues with Social Construction}

Secondly, econophysicists often ignore the socially constructed nature of economic systems as contrasted with physical ones. This has significant consequences for the interpretation of econophysical models' exact domain of application. Kovalev (2016) has argued against Georgescu-Roegen's (1971) thermodynamic model of economic scarcity by noting how the appeal to a mechanism of thermodynamic entropy is erroneous given that the boundaries of an economic system are not well-defined in the way they are in physical contexts. While Gallegati et al. (2006) acknowledges that several econophysicists' discovery of fat-tailed distributions "has now been established beyond doubt as a truly universal feature of financial markets" (2), they argue that most mechanisms posited by econophysicists are best understood as parsimonious models which help to ease certain calculations but do not reflect economic reality. There are no objective, mind-independent boundaries to social systems independent of our agreement amongst members of society to collectively regard aspects of reality as representing and having certain 'status functions' in social systems (e.g. that a piece of paper is collectively considered to be worth five dollars). One cannot understand how something such as money functions without understanding how humans come to regard money, and physical explanations will not aid such understanding at all; this is because economic explanations arguably require an appeal to 'reasons', via narrative explanations, and not merely causes (Hausman 2001).

This is not to say that there cannot be naturalistic explanations for economic phenomena, such as neuroscientific accounts of consumer preferences (Harrison \& Ross 2010). Rather, mechanisms in economics ought to be articulable within a framework that remains steadfastly sensitive to insights from fields such as history, sociology, political economy, and international relations. Mechanisms must therefore function to provide adequate explanations and not merely predictions; and such explanations ought to give a narrative account of how human collective intentionality plays a constitutive role in the reality of financial and economic phenomena. For example, while Sornette $(2003 \mathrm{a}, 6)$ defends the usage of log-periodic power laws in articulating phase transitions in market crashes, he nonetheless suggests five possible narrative explanations for why the 1987 crash occurred: a sudden rush of stop-loss orders from computer trading algorithms that had only recently started to be implemented en masse, the increasingly prevalent array of high-risk index and derivatives securities, insufficient liquidity, what was then a large US trade deficit, and a paradigmatic case of overvaluation. At the very least then, econophysical mechanisms must be supplemented with narrative explanations along these lines; currently, most econophysicists publishing in physics journals do not supplement their analyses with narrative explanations that describe the socially constructed features of economic systems. ${ }^{18}$

\footnotetext{
${ }^{18} \mathrm{~A}$ family of related objections have been made toward mainstream neoclassical economics as well,
} 


\subsection{Issues with Boundary Conditions}

Thirdly, it is unclear how to understand the parts and boundaries of the mechanisms being posited in econophysical models. Kuhlmann (2014) began a conversation in the philosophy of econophysics literature along these lines and has defended several econophysical models positing mechanisms, employing the term 'structural mechanisms'. ${ }^{19}$ Kuhlmann introduced an important distinction between 'chaotic behaviour' and 'robust complex behaviour', the former being a system whose evolution is hyper sensitive to initial conditions and the latter a system whose nonlinear interactions between constituents percolate upward generating system-wide coordination. He argued that financial markets exhibit both features and that there exist endogenous features of financial markets that generate statistical regularities, such as the analogy between trading behavior and the spin alignments of ferromagnets, that are sufficiently similar amongst financial markets around the world to warrant such regularities being regarded as 'stylized facts'. Furthermore, high quality theories positing structural mechanisms would directly take into account the role of collective intentionality, such as an acknowledgment that an analysis of merely the physical parts of, for instance, a credit card payment system would render void any explanation of how this system is a means of managing debt (i.e. a social construct serving a particular social purpose, and not a physical one) (Kuhlmann 2014, 1121). Structural mechanisms have two separate sub-structures: (i) start and boundary conditions and (ii) dynamics (1122); furthermore what counts as having discerned the existence of a bona fide econophysical mechanism is to have found a structural mechanism that is robust (i.e. the stylized facts of econophysics' theories obtain and are not sensitive to perturbations in the initial conditions) (1124).

Kuhlmann's account is a sophisticated and plausible articulation of recent econophysical models. However, several challenges remain for econophysicists positing structural mechanisms so understood. Firstly, most extant econophysical mechanisms do not sufficiently describe the features of collective intentionality in agents. Secondly, as argued above, what constitutes the start and boundary conditions is unclear in the case of a given financial system, especially when (a) financial systems are constantly evolving and changing and (b) we take into account the role of government in intervening on financial markets (i.e. a non-market participant) ${ }^{20}$ Recent work in both the philosophy of physics and philosophy of economics have noted how important boundary conditions are in understanding both physical and economic mechanisms, especially with respect to those mechanisms' ability to provide explanations of phenomena. In physics, the boundaries are not only the mereological, topological, and geometric boundaries of a physical system but boundaries on its solution space (Bursten 2021); in economics, these considerations apply with additional concerns regarding the boundaries of what is considered to be a

specifically from the 'critical realism' school of social science (Lawson 1997; Fleetwood 2004).

${ }^{19}$ I thank an anonymous referee for drawing my attention to this work.

${ }^{20}$ For example, see a recent institutional analysis in Volume 3, Issue 1 of the Journal of Financial Crises (2021) for a set of papers outlining in great detail how the Federal Reserve Bank of New York bailed out American International Group, Inc., one of the world's largest insurance corporations which was brought to the brink of bankruptcy in the 2008 financial crisis. 
'market' (e.g. the internet is a marketplace no less than a bazaar in Marrakech, and yet radically different in dynamics and structure) (Schabas 2009). This has significant consequences for attempts to find critical exponents for log-periodic power laws and find universality classes given that the boundaries of the system determine the calculation of correlation lengths, particularly with respect to what counts as adjacent elements of the lattice in renormalization group methods (Wilson 1979). What are considered 'adjacent traders' in a lattice is defined by econophysicists, such as JLS, as simply whichever group of other traders a given trader converses about financial matters with, which need not be geographically local (Johansen et al. 2000, 224). However, this is manifestly strongly disanalogous to the importance spatial contiguity plays in the determination of spin alignments in ferromagnets; the econophysical model is not as robust a finding in the financial systems they survey, compared to the physical systems, such that an analogous mechanism can be said to have been discerned. This is especially so when we consider that the alignment of spin in ferromagnetic phenomena is endogenous to the system's behaviour whereas JLS note that the phenomenon to be explained, namely a market crash, is the result of exogenous forces, making it all the more important that boundaries of the system be well-defined (Johansen et al. 2000, 223). In fact, the authors explicitly acknowledge a significant deficit of their model along these lines: "The relevant parameter is $\mathrm{K} / \sigma$. It measures the tendency towards imitation relative to the tendency towards idiosyncratic behavior...We do not know the dynamics that drive the key parameter of the system K...we would like to just assume that it evolves smoothly" (230).

Consider also Farjoun \& Machover (1983), who reinvigorated the 19th-century Marxist debate concerning the 'decline in the rate of profit' by employing concepts and mechanisms in statistical mechanics (40). Contrary to the influential views of Adam Smith and Joan Robinson, they claim that the proposition that the rate of profit in every industry of an economy tends toward equality is empirically untenable. Rather, the forces of capitalism generate at most a probability distribution for rates of profit in which an equilibrium occurs (52-53):

"The speed-behaviour of the gas particles is in fact quite reminiscent of the profit-behaviour of firms in a competitive capitalist economy...A state in which all the particles travel at the same speed is much too 'orderly' to be a state of equilibrium...The economists who assume a uniform rate of profit can be said, figuratively speaking, to ignore the 'law of entropy' regarding a system of perfect competition."

They argue that the structure of the profit-motivated behavior of firms is sufficiently similar to the behavior of gas particles so as to provide an explanation of why we do not observe uniformities in the rate of profit in the various sectors of the economy. It is in this sense that the mechanism of entropy is being non-trivially re-purposed for the study of economic phenomena.

As with Yakovenko's 'conservation of money' concept, Farjoun and Machover's form of imperialistic model transfer also fails. The mechanism of entropy is mechanistically 
transitive for many other mechanisms in physics, from the behavior of gas particles to large-scale cosmological models, which rely on the second law of thermodynamics. By way of contrast, it is implausible that a purported 'entropy law' of economics could ever be an initial mechanism in a much more complex chain of social mechanisms in a sufficiently analogous manner to the widespread transitivity of mechanisms in modern physics. This is largely because the boundaries of economic systems are not robust enough to permit the mechanism of entropy to legitimately hold. This is especially so given that it is unclear whether, for instance, we ought to include the earth's atmosphere as part of the economy or not, something increasingly being commodified through abstract financial instruments such as 'weather derivatives' (Thornes \& Randalls, 2007).

\subsection{Issues with Equilibrium}

Fourthly, there remains no consensus in contemporary econophysics on how to understand mechanisms involving equilibrium states of systems in econophysics given (a) competing definitions of equilibrium employed; (b) lack of clarity on how to determine when equilibria obtain; (c) a lack of sufficient evidence of the empirical adequacy of such models; (d) lack of clarity on boundary conditions. Some econophysicists, especially those constructing agent-based models, have defended the usage of equilibrium reasoning, as in the context of tax-evasion dynamical models based off of the Ising model of ferromagnetism: "[E]conophysics models may mimic results obtained by economics models and...both model types may lead to stable equilibrium situations (steady states), which are characterized by a prevailing positive rate of tax evasion" (Pickhardt \& Seibold 2014, 150). However, other econophysicists have criticized such reasoning as misapplying the statistical mechanical concept of equilibrium: "The advanced methods of statistical physics are confined to motions near statistical equilibrium whereas real financial markets exhibit no equilibrium whatsoever. Empirical evidence for statistical equilibrium has never been produced for any real market" (McCauley 2006, 605). MacAuley's criticisms are also directed towards research programs such as Drăgulescu \& Yakovenko (2000), and their econophysical model of monetary exchange, and Smith \& Foley's $(2008,27)$ defense of thermodynamic analogies in mainstream neoclassical economics: "Economic utility theory does not generally consider the possibility of individual economic agents being out of equilibrium in this sense, so that in utility theory the offer prices (marginal rates of substitution) of an economic agent are always well-defined. Thus at the level of representation, economic agents can only be considered analogous to thermodynamic subsystems in thermodynamic equilibrium." The situation in mainstream economics is no less contentious with Backhouse $(2004,296)$ noting four competing usages of equilibrium that have been used that have been inspired by physics: (i) absence of endogenous changes; (ii) balance of economic forces; (iii) correct expectations; (iv) absence of reasons for agents to change their behaviour. There is also the concern as to whether saddle points of a system constitute equilibria or not, even if they are unstable. Clarity regarding what it means for the state of a system to be in equilibrium is still forthcoming in econophysics and economics more generally. 


\subsection{Issues with Time Variables}

Fifthly, concerning the dynamical features of structural mechanisms, the role that time plays as a variable in the dynamics of several econophysical models is unclear. This is especially the case when equilibrium models such as Yakovenko (2016) posit equations from classical mechanics which are time-reversal invariant in the context of physical applications but which are manifestly not time-reversal invariant in the context of economics; this is something that, in fact, Yakovenko acknowledges is a deficit of his model (Yakovenko 2016, 3315). Indeed, there is a long history of physics transfer advocates importing time-reversible models in physics into economics, something which has been criticized by Cross (1995). ${ }^{21}$ Furthermore, while it is granted that a structural mechanism, in Kuhlmann's sense, exists only if there is robustness, in the sense of insensitivity to perturbations in initial conditions, econophysicists positing mechanisms arguably require an additional form of robustness to also hold: that the stylized fact obtain across a wide variety of historical and cultural contexts. On the one hand, in their systematic review Sinha \& Chakrabarti $(2012,53)$ claim that:

The bulk of the income distribution is well described by a Gibbs distribution or a lognormal distribution...This seems to be a universal feature - from ancient Egyptian society through 19th century Europe to modern Japan...from the advanced capitalist economy of the US to the developing economy of India.

On the other hand, most econophysical models focus on financial market data sets from the post World War II period, and primarily on North American, European, and Asian economies, with little analysis of Latin American, African, and Austronesian regions. Even for these data sets, there remains disagreement on to what extent econophysical models are more empirically adequate than mainstream economic ones (Gallegati et al 2006). While modest successes analyzing 20th-century financial market behaviour in the developed world may suggest potential promise for discerning econophysical mechanisms in economic reality, this attitude should be attenuated to at most a form of cautious optimism, considering the history of several widely respected economists failing to predict critically important economic phenomena, especially market crashes and economic recessions. ${ }^{22}$ There has yet to be a market crash in the future that has been

\footnotetext{
${ }^{21}$ In this same paper, Cross further criticizes several prominent usages of time-irreversible mechanisms which have been appropriated from physics for usage in economics, such as hysteresis effects in electromagnetic phenomena and a purported analogy to international trade in the presence of exogenous shocks (Cross 1995, 130).

${ }^{22}$ For example, consider Irving Fisher's well known false prediction in 1929 that the stock market would not crash (Sornette 2003b, 13-14), when it did, or 1995 Nobel Memorial Prize winner Robert Lucas's naive remark just prior to the 2007-2008 recession that "the central problem of depression-prevention has been solved" (Krugman, 2009). This is so despite Joseph Schumpeter once remarking of Fisher: "I venture to predict that his name will stand in history principally as the name of this country's [the United States] greatest scientific economist" ([1952] 1997, 223). If mainstream economics cannot be relied upon to make predictions of critical economic phenomena such as market crashes, it is unclear that alternative approaches such as econophysics should be optimistic of their ability to do so either.
} 
predicted by an econophysicist; at most, there have been retrograde explanations for market crashes such as the 1929, 1987, and 2007 financial crises.

\subsection{Issues with Interventionist Accounts of Causation}

Sixthly, mechanisms in the natural and social sciences typically explain, at least in principle, if not in practice, how knowledge of a mechanism allows one to intervene on the system. In medicine, a field characterized by a prevalence of mechanistic explanations, mainstream theories of the mechanism underpinning, for instance, type- 1 diabetes mellitus posit that those with diabetes have a pancreas which emits less insulin than in non-diabetic individuals, allowing medical practitioners to intervene by prescribing insulin to mitigate harmful symptoms (Rother 2007). In economics, the Monetarist school of macroeconomics, of which the Canadian Government largely follows, suggests that the rate of inflation is strongly correlated to the money supply; it is the Bank of Canada's explicit policy that by controlling interest rates, the bank can intervene on the Canadian economy in order to reach inflation targets (Ragan 2012). In both cases, the mechanisms underpinning the relationship some dependent variable $Y$ has with respect to some set $S$ of independent variables is understood well enough in terms of its parts such that intervention upon elements of $S$ can lead to targeted values of $Y$.

It is acknowledged that in practice, it is challenging to enact an intervention into a financial system; hence, our focus will be on idealized situations in which interventions are alleged to be possible. Kuhlmann $(2014,1123 ; 2019,189-190)$ argues that an articulation of the parts of an econophysical model are inconsequential as compared to the macro-level systemic behavior generating statistical stylized facts. The point of disagreement here therefore concerns the extent at which the micro constituents require further elucidation in order to count as a proper mechanism. This is important given that it remains unclear in many econophysical models how one is supposed to use knowledge of mechanisms that have been posited to intervene in the system.

Returning to Juhn et al. (2018) as an example, the authors argue that "our interpretation of the JLS model as one that yields causal explanations suggests methods by which policymakers could intervene on the economy in order to prevent crashes or to halt the spread of one...[T]he model provides an explanation of crashes that is both causal...and reductive" (4480), employing an 'interventionist account of causation' in the sense of a popular view defended by Woodward (2003). A virtue of their approach is that they describe, at least in principle, how one might intervene to inhibit market crashes, suggesting for instance that the New York Stock Exchange 'trading curb' is designed to stop trading when high volatility of the Dow Jones Industrial Average is observed (Jhun et al. 2018, 4499). However, what these authors do not explain is the connection between critical phase transitions and such a policy intervention. They gesture at the JLS model providing insights into 'long-range correlations between traders'

While it is a contention by econophysicists that mainstream economics is fundamentally flawed in its approach, especially in avoiding usage of fat-tailed distributions, strong claims require stronger evidence than is arguably on hand. 
without providing guidance on how to measure this nor do they explain what constitutes a sufficient threshold of volatility indicative of an impending crash. There is also no mention of other evidently crucial parts of the 1987 crash they attempt to explain, such as the means of communication in which traders come to know that prices are falling rapidly or how traders communicate with one another via telecommunications. This is especially so when a report by the United States Federal Reserve Board argued that: "There were two [computer] program trading strategies that have often been tied to the stock market crash," noting the role nascent algorithmic trading played, raising significant doubts that the econophysical explanation focuses on the relevant parts of the actual mechanism underpinning the crash (Carlson 2006, 4). ${ }^{23}$

Note that my objection would fail if the model were less ambitious and aimed only at providing an account of a structural analogy; however, a significant challenge remains given their attempt to demonstrate that the JLS model is a 'causal explanation' of market crashes (Jhun et al. 2018, 4498-4499). An adequate causal explanation should not leave out salient parts of the target phenomenon; the volume of trading information and the lack of existing financial and computing infrastructure to handle real-time transactions are key components of the mainstream narratives regarding the causal mechanisms of the 1987 market crash's occurrence. Hence, several related challenges arise for econophysicists positing causal mechanisms given a lack of clarity on how such mechanisms admit of appropriate intervention.

\subsection{Issues with Controlled Experiments}

Seventhly, the relevance between the articulation of a system's parts and the ability to intervene on those parts suggests difficulties for econophysicists wishing to advocate controlled experiments as a means of finding mechanisms in economic reality. In a systematic review, Huang (2015) writes: "Physics may be a candidate discipline for economics to absorb such ideas and methods. In this sense, economics needs physics, so that people might scrutinize some economic problems from a different perspective, thus yielding different insights...[I]t seems unbelievable that in the future, econophysics without controlled experiments could be as mature as traditional physics" (4-5). Huang defines a controlled experiment as "experiments conducted in the laboratory, which produce data by tuning one (or few) variable(s)/condition(s)...revealing cause-effect relationships between the factors(s)" (5). For example, Huang discusses a 'minority game' which is essentially a species of behavioral economics study in which an odd number of $n$ university students are instructed to use computer terminals and input decisions regarding whether to enter room $\mathrm{A}$ or $\mathrm{B}$, with a point given if the room entered has less people

\footnotetext{
${ }^{23}$ It is highly doubtful many scholars of finance would find an alleged physical explanation explanatory for market crashes. In a systematic review of what they describe as pervasive 'physics envy' in mainstream economics and finance, Lo \& Mueller (2010, 50-57) provide a detailed discussion of several competing narrative explanations of the 2007-2008 financial crisis. See also Kotz (2009) for a detailed 'institutional economics' analysis that, according to Google Scholar, has been cited 565 times at the time of writing, and which articulates the mechanisms, and their respective parts, of the effects of neoliberal policies leading to the crisis, that have nothing to do with analogies from physical mechanisms.
} 
than the other room. The thought here is that one can extrapolate from the findings of this small-scale 'minority game' experiment to understand the complexities of stock market activity. This is a prototypical example of an econophysical experiment from which agent-based models are developed from. ${ }^{24}$

However, in these contexts, such studies are best interpreted as psychology experiments and not as physics experiments; and hence, the strengths and weaknesses of such experiments apply. ${ }^{25}$ While there are many weaknesses of such a method, the most salient is that the degree at which variables can be controlled in most physics laboratories is vastly greater than in the case of psychology experiments conducted on human beings; this poses a significant challenge for Huang $(2015,5)$ who argues that the 'tuning' of parameters in physical experiments is sufficiently similar in the psychological experiments of econophysics. There are significant ethical limitations upon human experimentation that render the method of controlled experiments an implausible epistemic standard for econophysicists to set, insofar as one believes in this method specifically as an extension of experimental methods in physics, where ethics does not inhibit our often extreme manipulation of particles. The degrees of freedom are also innumerable in social systems, even in systems as comparatively simple as the confines of a psychology laboratory; while the degrees of freedom in physics are also quite high, they are far more epistemically tractable than in the case of financial markets given the abundance of understanding physicists have of physical systems' micro behavior. ${ }^{26}$ Hence, while experimental psychology is a legitimate scientific discipline, it is not plausible to see this discipline as a guide to discerning econophysical mechanisms; this is especially so if one wants to enhance the scientific legitimacy of econophysics, given that controlled experiments in psychology are insufficiently similar in design to those in physics. Rather, it would be more prudent to respect the complete autonomy of psychology as a discipline, extrapolate from such findings (when justified) to larger scale social behavior, and apply statistical techniques to find associations between behavior in one locale with that of another to discern mechanisms. But in no sense, in the way Huang discusses, is this an extension of the method of controlled experiments in physics, anymore than behavioral economics and empirical psychology are an extension of physics either.

\footnotetext{
${ }^{24}$ See for instance Challet et al. (2001) for a representative minority game study conducted by econophysicists. See also Chakraborti et al. (2011) for a systematic review of agent-based models in econophysics.

${ }^{25}$ See Guala (2005) for a detailed overview of the methodology of behavioral economic study and the extent at which what occurs in the laboratory can be rationally believed to occur outside the laboratory and in the real economic world.

${ }^{26}$ Finance scholars Lo \& Mueller (2010) agree, writing in their criticisms of physics transfer in mathematical finance that: "Today's financial system is considerably more complex than ever before, requiring correspondingly greater concerted effort and expertise to overhaul. By comparison, the Large Hadron Collider - as complex as it is — is a much simpler system...the accelerator, detectors, and computers that constitute the Collider are governed by physical laws that are either perfectly certain or fully reducibly uncertain" (49).
} 


\section{Conclusion}

While not all econophysicists believe in such strong views about mechanisms, many do and justification for such claims is often found wanting. I therefore disagree with Kuhlmann (2019, 186, emphasis added) who claims: "The possibility of the fruitful transfer of physics' strategies into the domain of economics rests exclusively on structural similarities, and has nothing to do with physics being the most fundamental science." On the one hand, there is a sense in which, as section 3.1 of my paper illustrates, structural analogies between economic and physical phenomena are manifested only at the level of mathematical transfer in many econophysical theories; this much Kuhlmann and I agree on. However, as I have argued here, it is also the case that there are many econophysicists who claim that economic reality ought to be understood as nonautonomous and as merely an extension of physical reality, and that this is motivated by the belief that physical phenomena are ontologically fundamental compared to economic phenomena.

Contemporary econophysics remains a chimera discipline advocating a diversity of methods and models from physics for the purposes of explaining and predicting economic phenomena in a much stronger sense than the 19th-century figures surveyed. Often, instances of mathematical formalism transfer are justified, while the transfer of physical mechanisms is not. A charitable interpretation of these instances of methodological transfer forces us to consider what exactly is being transferred and take seriously the potentially rewarding prospects of genuinely novel applications of methods from another discipline. The history of science is no stranger to such occurrences. Assessing the adequacy of instances of method transfer ought to depend entirely on our explanatory and predictive aims and not on the basis of prejudices concerning the ostensible irrelevance of one field's methods to that of another field's phenomena. Nonetheless, greater caution should be exercised in ensuring that the ontological assumptions underpinning the mechanisms in one source field is justified in being transferred to the target field. Econophysicists often overlook important subtleties when borrowing mathematical models from physics by exporting a problematic and unjustified ontology in the process. On the other hand, striving for purely instrumentalist goals of prediction is where contemporary econophysics shines and remains potentially promising. In this sense, I follow economist Frank Knight's comment as early as 1921 that: "The entire application of mechanical categories to economic analysis requires drastic overhauling ([1921] 1964, xxiii).

\section{References}

[1] Aldrich, J. (1987). Jevons as Statistician: The Role of Probability. The Manchester School, 55(3):233-256.

[2] Arioli, Gianni. \& Valente, Giovanni. (2021). What is really quantum in quantum econophysics? Philosophy of Science, DOI: https://doi.org/10.1086/713921. 
Accessed May 29, 2021.

[3] Baaquie, B. (2004). Quantum Finance: Path Integrals and Hamiltonians for Options and Interest Rates. Cambridge University Press.

[4] Baaquie, B. (2018). Quantum Field Theory for Economics and Finance. Cambridge University Press.

[5] Backhouse, Roger E. (2004). History and equilibrium: A partial defense of equilibrium economics. Journal of Economic Methodology, 11(3), 291-305.

[6] Barbé, L. (2010). Francis Ysidro Edgeworth: A Portrait with Family and Friends. Edward Elgar Publishing Limited.

[7] Bouatta, N., \& Butterfield, J. (2014). Renormalization for Philosophers. ArXiv, URL: https://arxiv.org/pdf/1406.4532.pdf. 1-48. Accessed May 28, 2021.

[8] Boumans, M. (1993). Paul Ehrenfest and Jan Tinbergen: A Case of Limited Physics Transfer. History of Political Economy, 25, 131-156.

[9] Bradley, S. \& Thébault, K. (2019). Models on the move: Migration and imperialism. Studies in History and Philosophy of Science: Part A, 77, 81-92.

[10] Buchanan, M. (2013). What has econophysics ever done for us? Nature Physics, 9,317 .

[11] Bursten, J. (2021). The Function of Boundary Conditions in the Physical Sciences. Philosophy of Science, 88, 234-257.

[12] Carlson, M. (2006). A Brief History of the 1987 Stock Market Crash with a Discussion of the Federal Reserve Response. Finance and Economics Discussion Series: 2007-13 URL: https://www.federalreserve.gov /pubs/feds/2007/200713/200713pap.pdf. Accessed June 1, 2021.

[13] Cartwright, N., \& Deaton, A. (2018). Understanding and misunderstanding randomized controlled trials. Social Science $\&$ Medicine, 210, 2-21.

[14] Chakraborti, A., Toke, I., Patriarca, M., \& Abergel, F. (2011). Econophysics review: II. Agent-based models. Quantitative Finance, 11(7), 1013-1041.

[15] Challet, D., Marsili, M., \& Zhang, Y. (2001). Stylized facts of financial markets and market crashes in Minority Games. Physica A, 294, 514-524. 
[16] Cockshott, W., Allin P., Cottrell, F., Michaelson, G. J., Wright, I. P., \& Yakovenko, V. M. (2009). Classical Econophysics. Routledge.

[17] Cross, R. (1995). Metaphors and time reversibility and irreversibility in economic systems. Journal of Economic Methodology, 2(1),8 123-134.

[18] Dimand, R. (2013). David Hume and Irving Fisher on the quantity theory of money in the long run and the short run. The European Journal of the History of Economic Thought, 20(2), 284-304.

[19] Duarte, F. J., Machado J. A., \& Duarte, G. M. (2010). Dynamics of the Dow Jones and the NASDAQ stock indexes. Nonlinear Dynamics, 61, 691-705.

[20] Edgeworth, F. (1877). New and Old Methods of Ethics. Oxford: James Parker and Co.

[21] Edgeworth, F. (1881). Mathematical Psychics. C. Kegan Paul \& Co.

[22] Edgeworth, F. (1884). The Rationale of Exchange. Journal of the Statistical Society of London, 47(1), 164-166.

[23] Edgeworth, F. (1893). Review of Mathematical Investigations in the Theory of Value and Prices. The Economic Journal, 112, 108-109.

[24] Edgeworth, F. (1922). The Philosophy of Chance. Mind, 31(123), 257-283.

[25] Edgeworth, F., \& Pareto, V. ([1896] 2008). Controversy Between Pareto and Edgeworth. Giornale degli Economisti e Annali di Economia, Nuova Serie, 67(121), 425-440.

[26] Farjoun, E. \& Machover, M. (1983). Laws of Chaos: A Probabilistic Approach to Political Economy. Verso Editions and NLB.

[27] Fisher, I. ([1892] 1925). Mathematical Investigations in the Theory of Value and Price. August M. Kelly.

[28] Fleetwood, S. (1999). Critical Realism in Economics. Routledge.

[29] Gabaix, X. (2016). Power Laws in Economics: An Introduction. The Journal of Economic Perspectives, 30 (1), 185-205. 
[30] Gallegati, M., Keen, S., Lux, T., \& Ormerod, P. (2006). Worrying trends in econophysics. Physica A: Statistical Mechanics and its Applications, 370(1), $1-6$.

[31] Gelfert, A. (2016). How to Do Science with Models. Springer.

[32] Georgescu-Roegen. N. (1971). The Entropy Law and the Economic Process. Harvard University Press.

[33] Gingras, Y., \& Schinckus, C. (2012). The Institutionalization of Econophysics in the Shadow of Physics. Journal of the History of Economic Thought, 34(1), 109-130.

[34] Greaves, H. (2007). Probability in the Everett Interpretation. Philosophy Compass, 2(1), 109-128.

[35] Guala, F. (2005). The Methodology of Experimental Economics. Cambridge University Press.

[36] Harrison, G., \& Ross, D. (2010). The methodologies of neuroeconomics. Journal of Economic Methodology, 17(2), 185-196.

[37] Hausman, D. (2001). Explanation and Diagnosis in Economics. Revue internationale de philosophie, 217, 311-326.

[38] Hedström, P., \& Swedberg, R. (1996). Social Mechanisms. Acta Sociologica, 39(3), 281-308.

[39] Huang, J. (2015). Experimental econophysics: Complexity, self-organization, and emergent properties. Physics Reports, 564, 1-55.

[40] Ingrao, B., \& Israel, G. (1990). The Invisible Hand: Economic Equilibrium in the History of Science. The MIT Press.

[41] Isard, W. (1954). Location Theory and Trade Theory: Short-Run Analysis. The Quarterly Journal of Economics, 68 (2), 305-320.

[42] Jevons, W. ([1871] 1970). The Theory of Political Economy. Penguin Classics.

[43] Jevons, W. (1873). The Philosophy of Inductive Inference. Fortnightly Review, 14(18), 457-476. 
[44] Jevons, W. (1883). The Principles of Science: A Treatise on Logic and Scientific. Method. Macmillan and Co.

[45] Jevons, W. (1886). Letters \& Journals. Macmillan and Co.

[46] Jhun, J., Palacios, P., \& Weatherall, J. (2018). Market crashes as critical phenomena? Explanation, idealization, and universality in econophysics. Synthese, 195, 4476-4505.

[47] Johansen, A., Ledoit, O., \& Sornette, D. (2000). Crashes as critical points. International Journal of Theoretical and Applied Finance, 3(2), 219-255.

[48] Jovanovic, F., \& Schinckus, C. (2013). The Emergence of Econophysics: A New Approach in Modern Financial Theory. History of Political Economy, $45(3), 443-474$.

[49] Jovanovic, F., \& Schinckus, C. (2017). Econophysics and Financial Economics: An Emerging Discipline. Oxford University Press.

[50] Kincaid, H. (2021). Mechanisms, good and bad. Theoria, 36(2), 173-189.

[51] Knight, F. ([1921] 1964). Risk, Uncertainty and Profit. August M. Kelly.

[52] Kovalev, A. (2016). Misuse of thermodynamic entropy in economics. Energy, 100, 129-136.

[53] Krugman, P. (2009). How Did Economists Get It So Wrong? The New York Times. URL: https://www.nytimes.com/2009/09/06/magazine/ 06Economic-t.html. Accessed June 1st, 2021.

[54] Kuhlmann, Meinard. (2014). Explaining Financial Markets in Terms of Complex Systems. Philosophy of Science, 81, 1117-1130.

[55] Kuhlmann, Meinard. (2019). Crossing Boundaries: Why Physics Can Help Understand Economics. In Mechanistic Explanations in Physics and Beyond, 183-205. Springer Nature Switzerland.

[56] Kutner, R., Ausloos, M., Grech, D., Matteo, T., Schinckus, C., \& Stanley, H. E. (2019). Econophysics and sociophysics: Their milestones \& challenges. Physica A, 516, 240-253.

[57] Lawson, T. (1997). Economics and Reality. Routledge. 
[58] Leng, N., \& Li, J. (2020). Forecasting the crude oil prices based on Econophysics and Bayesian approach. Physica A, 554, 1-13.

[59] Lo, A., \& Mueller, M. (2010). Warning: Physics Envy May Be Hazardous To Your Wealth! Journal of Investment Management, 8(2), 13-63.

[60] Machamer, P., Darden, L., \& Craver, C. (2000). Thinking About Mechanisms. Philosophy of Science, 67, 1-25.

[61] Mandelbrot, B. (1962). Sur certains prix spéculatifs: Faits empiriques et modél basé sur les processus stables additifs non gaussiens de Paul Lévy. Comptes Rendus de l'Académie des Sciences [Meeting of June 4], 3968-70.

[62] Mantegna, R., \& Stanley, H. (2004). An Introduction to Econophysics: Correlations and Complexity in Finance. Cambridge University Press.

[63] Marchionni, C., \& Reijula, S. (2019). What is mechanistic evidence, and why do we need it for evidence-based policy? Studies in History and Philosophy of Science Part A, 73, 54-63.

[64] McCauley, J. (2006). Response to "Worrying Trends in Econophysics". Physica A, 371, 601-609.

[65] Mirowski, P. (1984). Physics and the 'marginalist revolution.' Cambridge Journal of Economics, 8, 361-379.

[66] Mirowski, P. (1988). Energy and Energetics in Economic Theory: A Review Essay. Journal of Economic Issues, 22(3), 811-830.

[67] Mirowski, P. (1989). More Heat Than Light. Cambridge University Press.

[68] Pickhardt, M., \& Seibold, G. (2014). Income tax evasion dynamics: Evidence from an agent-based econophysics model. Journal of Economic Psychology, 40, 147-160.

[69] Ragan, C. (2012). Financial Stability: The Next Frontier for Canadian Monetary Policy. C.D. Howe Institute, 338, 1-16.

[70] Richmond, P., Mimkes, J., \& Hutzler, S. (2013). Econophysics and Physical Economics. Oxford University Press. 
[71] Rickles, D. (2007). Econophysics for philosophers. Studies in History and Philosophy of Modern Physics, 38, 948-978.

[72] Rickles, D. (2011). Econophysics and the Complexity of Financial Markets. In Philosophy of Complex Systems. 531-565. Elsevier.

[73] Rosser, J. B. (2016). Entropy and econophysics. Eur. Phys. J. Special Topics, 255, 3091-3104.

[74] Rother, K. (2007). Diabetes Treatment - Bridging the Divide. New England Journal of Medicine, 356(15), 1499 - 1501.

[75] Russo, F., \& Williamson, J. (2007). Interpreting causality in the health sciences. International Studies in the Philosophy of Science, 21, 157-170.

[76] Samuelson, P. ([1947] 1971). Foundations of Economic Analysis. Oxford University Press.

[77] Sãvoiu, G., \& Andronache, C. (2013). The Potential of Econophysics for the Study of Economic Processes. In Econophysics Background and Applications in Economics, Finance, and Sociophysics. 91-133. Elsevier.

[78] Schabas, M. (1984). The "Worldly Philosophy" of William Stanley Jevons. Victorian Studies, 28(1), 129-147.

[79] Schabas, M. (1990). A World Ruled By Number: William Stanley Jevons and the Rise of Mathematical Economics. Princeton University Press.

[80] Schabas, M. (2009). Constructing 'The Economy'. Philosophy of Social Sciences, 39(1), 3-19.

[81] Schinckus, C. (2010). Is econophysics a new discipline? The neopositivist argument. Physica A, 389, 3814-3821.

[82] Schinckus, C. (2018). Toward a Unifying Perspective on Economic Complexity: The Contribution of Chinese Econophysics Community. Theoretical Economics Letters, 8, 609-625.

[83] Schumpeter, J. (1997). Ten Great Economists: From Marx to Keynes. Routledge.

[84] Slanina, F. (2014). Essentials of Econophysics Modelling. Oxford: Oxford University Press. 
[85] Sinha, S., \& B. Chakrabarti. (2012). Econophysics: An Emerging Discipline. Economic and Political Weekly, 47(32), 44-65.

[86] Smith, A. (1776/2012). Wealth of Nations. Wordsworth Editions Limited.

[87] Smith, E., \& Foley, Duncan. (2008). Classical thermodynamics and economic general equilibrium theory. Journal of Economic Dynamics \& Control, 32, 7-65.

[88] Sornette, D. (2003a). Critical market crashes. Physics Reports, 278, 1-98.

[89] Sornette, D. (2003b). Why Stock Markets Crash. Princeton University Press.

[90] Sornette, D. (2014). Physics and financial economics (1776-2014): puzzles, Ising and agent-based models. Reports on Progress in Physics, 77, 1-28.

[91] Stigler, S. (1977). Francis Ysidro Edgeworth, Statistician. Journal of the Royal Statistical Society, 141(3), 287-322.

[92] Stigler, S. (1986). The History of Statistics: The Measurement of Uncertainty before 1900. The Belknap Press of Harvard University Press.

[93] Tarasov, V. (2020). Fractional econophysics: Market price dynamics with memory effects. Physica A, 557, 1-16.

[94] Thébault, K., Bradley, S., \& Reutlinger, A. (2018). Modelling Inequality. British Journal for the Philosophy of Science, 79, 691-718.

[95] Thornes, J., \& Randalls, S. (2007). Commodifying the Atmosphere: 'Pennis from Heaven'? Geografiska Annaler. Series A., 89(4), 273-285.

[96] Urbach, P. (1993). The Value of Randomization and Control in Clinical Trials. Statistics in Medicine, 12, 1421-1431.

[97] Weatherall, J. (2013). The Physics of Wall Street. Houghton Mifflin Harcourt.

[98] Wilson, K. (1979). Problems in Physics with Many Scales of Length. Scientific American, 241(2), 158-179.

[99] Woodward, J. (2003). Making Things Happen: A Theory of Causal Explanation. Oxford University Press.

[100] Woolridge, J. (2019). Introductory Econometrics: A Modern Approach. Cengage Learning. 
[101] Yakovenko, V. (2016). Monetary economics from econo-physics perspective. Eur. Phys. J. Special Topics, 225, 3313-3335.

[102] Yegerov, Y. (2007). Econo-physics: A Perspective of Two Matching Sciences. Evol. Inst. Econ. Rev., 4(1), 143-170.

[103] Yu, T., \& Li, H. (2010). Econophysics Research in China. Science 83 Culture, 76(9-10), 391-394. 